\title{
TAK1 regulates Paneth cell integrity partly through blocking necroptosis
}

\author{
AN Simmons ${ }^{1}$, R Kajino-Sakamoto ${ }^{1,2}$ and J Ninomiya-Tsujii, ${ }^{* 1}$
}

Paneth cells reside at the base of crypts of the small intestine and secrete antimicrobial factors to control gut microbiota. Paneth cell loss is observed in the chronically inflamed intestine, which is often associated with increased reactive oxygen species (ROS). However, the relationship between Paneth cell loss and ROS is not yet clear. Intestinal epithelial-specific deletion of a protein kinase Tak1 depletes Paneth cells and highly upregulates ROS in the mouse model. We found that depletion of gut bacteria or myeloid differentiation factor 88 (Myd88), a mediator of bacteria-derived cell signaling, reduced ROS but did not block Paneth cell loss, suggesting that gut bacteria are the cause of ROS accumulation but bacteria-induced ROS are not the cause of Paneth cell loss. In contrast, deletion of the necroptotic cell death signaling intermediate, receptor-interacting protein kinase 3 (Ripk3), partially blocked Paneth cell loss. Thus, Tak1 deletion causes Paneth cell loss in part through necroptotic cell death. These results suggest that TAK1 participates in intestinal integrity through separately modulating bacteria-derived ROS and RIPK3-dependent Paneth cell loss.

Cell Death and Disease (2016) 7, e2196; doi:10.1038/cddis.2016.98; published online 14 April 2016

TAK1 (MAP3K7) is a member of mitogen-activated protein kinase kinase kinase (MAP3K), and an indispensable signaling intermediate of proinflammatory cytokine and Toll-like receptor (TLR)/NOD-like receptor signaling pathways leading to activation of transcription factors, NF- $K B$ and $A P-1$ (reviewed by Mihaly et al. ${ }^{1}$ ). NF-KB and AP-1 induce expression of a number of proinflammatory and cell survival genes including several antioxidant genes. ${ }^{2}$ TAK1 was also found to regulate a redox transcription factor, nuclear factor erythroid 2 (NF-E2)-related factor 2 (Nrf2). ${ }^{3}$ The levels of Nrf2 protein and its target gene expression were downregulated in Tak1-deficient tissue culture cells and intestinal epithelium. ${ }^{3}$ Thus, through these transcription factors, TAK1 participates in the maintenance of the cellular antioxidant system. Deletion of Tak1 impairs the cellular redox balance resulting in reactive oxygen species (ROS) accumulation in cultured cells. ${ }^{4-6}$ Tak1 deficiency causes cell death primarily through apoptosis, ${ }^{7}$ but also induces a regulated type of necrosis so-called necroptosis. ${ }^{8-11}$ Increased ROS are causally associated with apoptosis in Tak1-deficient cells, , ,5,12 whereas the mechanism by which Tak1 deficiency induces necroptosis is not yet clear.

In a mouse model, intestinal epithelial-specific Tak1 deletion causes cell death, severe inflammatory conditions and perinatal animal lethality. ${ }^{13}$ Ablation of the proinflammatory cytokine TNF by tumor necrosis factor 1 receptor 1 (Tnfr1) gene deletion effectively alleviates inflammation. Adult mice harboring intestinal epithelial-specific Tak1 deletion on
$\mathrm{Tnfr}^{-/}$background do not show observable health problems. ${ }^{14}$ However, the Tak1-deficient intestine still exhibits increased apoptosis in the crypt of the ileum and milder inflammatory conditions, which are similar to human ileitis. ${ }^{3}$ ROS are highly increased in the Tak1-deficient intestinal epithelium even on a Tnfr $1^{-/}$background. ${ }^{3}$ Furthermore, we found that almost no Paneth cells were observed in the Tak1deficient small intestine (shown in the current study). Paneth cells reside at the base of the crypts in the small intestine and are specialized to secret antimicrobial enzymes and peptides such as lysozyme $\mathrm{C}$ and defensins, which control commensal microbiota. ${ }^{15}$ Paneth cells are a unique cell type among the specialized intestinal epithelial cells, which have a very long life span of around 6-8 weeks, while other cells are constantly renewed about every 3-6 days in the mouse intestinal epithelium. ${ }^{16,17}$ Inflammatory bowel disease (IBD) is a group of chronic inflammatory diseases of the intestine, which is characterized by increased ROS in the intestinal epithelium and is sometimes associated with degradation of Paneth cells. ${ }^{18,19}$ One type of IBD, Crohn's disease, is specifically characterized by ileitis and dysfunction of Paneth cells, which resemble the Tak1-deficient intestinal epithelium. In the current study, we sought to determine the mechanism by which Tak1 deficiency causes IBD-like pathology, that is, increased ROS and loss of Paneth cells. We postulated two scenarios: one is that Tak1 deficiency causes ROS accumulation because of an impaired cellular redox system, which is the cause of Paneth cell loss; the other is that Tak1 deficiency

\footnotetext{
1'Department of Biological Sciences, North Carolina State University, Raleigh, NC 27695-7633, USA

*Corresponding author: J Ninomiya-Tsuji, Department of Biological Sciences, North Carolina State University, Raleigh, NC 27695-7633, USA. Tel: 919 5131 586; Fax: 9195157 169; E-mail: Jun_Tsuj@ @ncsu.edu

${ }^{2}$ Current address: Division of Molecular Pathology, Aichi Cancer Center Research Institute, Nagoya, Aichi 464-8681, Japan.

Abbreviations: FADD, Fas-associated protein with death domain; IBD, inflammatory bowel disease; MAP3K, mitogen-activated protein kinase kinase kinase; Myd88, myeloid differentiation factor 88; NQ01, NADPH quinone oxidoreductase-1; Nrf2, Nuclear factor erythroid 2 (NF-E2)-related factor 2; P, postnatal day; RIPK3, receptorinteracting protein kinase 3; ROS, reactive oxygen species; TLR, Toll-like receptor; TNFR1, tumor necrosis factor 1 receptor 1; TRIF, TIR-domain-containing adapterinducing interferon- $\beta$; TUNEL, terminal deoxynucleotidyl transferase dUTP terminal nick-end labeling

Received 21.12.15; revised 16.3.16; accepted 21.3.16; Edited by A Finazzi-Agrò
} 
causes Paneth cell death, which results in the disruption of normal gut microbiota leading to increased ROS. A better understanding of the relationship between two major IBD disorders: ROS and Paneth cell loss could shed new insights into IBD pathogenesis, which is still largely undetermined.

\section{Results}

Intestinal epithelial-specific deletion of Tak1 depletes Paneth cells. To determine the mechanism by which Tak1 deletion causes IBD-like intestinal injury, we initially re-evaluated the intestinal morphology in the Tak1-deficient intestinal epithelium. We used mice having intestinal epithelium-specific Tak1 deletion on a Tnfr1 null background $\left(\mathrm{Tak} 1^{\mathrm{IE}-\mathrm{KO}} \mathrm{Tnfr}^{-/-}\right)$. Although some but not all Tak1 ${ }^{\mathrm{IE}-\mathrm{KO}}$ $\mathrm{Tnfr}^{-/}$mice develop inflammatory conditions around postnatal day $15-17,{ }^{13}$ once they reach the adult stage, Tak $1^{\mathrm{IE}-\mathrm{KO}}$ $\mathrm{Tnfr}^{-1-}$ mice do not show appreciable abnormalities. ${ }^{14}$ Intestinal epithelium with compound deletion of Tak1 and Tnfr1 exhibits only a mild increase of inflammatory cytokines, IL-1 and IL-6, and a chemokine, C-X-C motif ligand 2 . $^{3}$ However, Tnfr1 deletion does not reduce the number of dying cells or the level of ROS in the Tak1-deficient intestinal epithelium. ${ }^{3}$ We previously reported that goblet and enteroendocrine cells are normally developed around birth and the numbers of those cells are not altered by Tak1 deficiency at postnatal day 0 (P0). ${ }^{13}$ In wild-type mice, Paneth cells become detectable around 2-3 weeks of age concomitantly with the establishment of commensal microbiota. ${ }^{20}$ To detect Paneth cells, we performed immunofluorescence staining of lysozyme, which is selectively expressed in Paneth cells, and Alcian blue staining, which detects acidic mucins in goblet cells and granules in Paneth cells. ${ }^{21}$ At P17, as Paneth cells are not yet fully matured, we observed two or three lysozymepositive cells and weak Alcian blue staining at the base of crypt in both no-Cre Tnfr1 ${ }^{-/-}$and Tak1 $1^{\mathrm{IE}-\mathrm{KO}} \mathrm{Tnfr}^{-/-}$ (Figure 1a, bottom panels, Supplementary Figures S1A and $1 \mathrm{~B}$, and also see ref. 13). Thus, Paneth cells are developed even in Tak1-deficient intestinal epithelium. Architecture of the small intestine in Tak1 $1^{\mathrm{IE}-\mathrm{KO}} \mathrm{Tnfr}^{-/}{ }^{-1}$ mice was largely intact at P17 (Figure 1a, upper panels and also see ref. 13). The total number of intestinal epithelial cells per crypt did not decrease in Tak1 ${ }^{\mathrm{IE}-\mathrm{KO}} \mathrm{Tnfr}^{-/-}$mice (Figure 1a, upper panels and also see ref. 13). These indicate that Tak1 deficiency does not impair intestinal epithelial stem cells or their ability to differentiate toward specialized intestinal epithelial cells including Paneth cells. However, we found that Paneth cells were completely depleted in the adult (3-month-old) Tak $1^{\mathrm{IE}-\mathrm{KO}}$ $\mathrm{Tnfr}^{-/}$mice (Figure 1b). Thus, Paneth cells can complete their differentiation processes in the Tak1-deficient intestinal epithelium but they are not maintained.

To further investigate Paneth cell loss in the Tak1-deficient intestinal epithelium, we used mice carrying an inducible intestinal epithelial-specific Tak1 gene deletion system on a Tnfr $1^{-1-}$ background, villin.CreER ${ }^{\text {T2 }}$ Tak1 $1^{\text {flox/flox }}$ Tnfr $^{-1-}$ $\left(\right.$ Tak1 $\left.{ }^{\mathrm{IE}-\mathrm{IKO}} \mathrm{Tnfr}^{-/-}\right)$. In this system, TAK1 is intact without an inducer of gene deletion, tamoxifen, and, upon intraperitoneal injection of tamoxifen for 3 consecutive days (day 3 ), intestinal epithelium TAK1 protein was diminished and Tak1 deletion was afterward maintained without additional tamoxifen treatment (Supplementary Figure S1C). We found that Paneth cells (granulated cells in the base of crypts) were gradually decreased starting at day 4 after tamoxifen treatment and depleted around day 7 (Figure 1c). As heterozygous deletion of Tak1, Villin.CreER ${ }^{T 2}$ Tak $1^{\text {flox/+ }} \operatorname{Tnfr}^{-/-}$, did not exhibit any abnormality with tamoxifen treatment (Supplementary Figure S1D), Paneth cell loss is dependent on Tak1 deletion but not on artifacts from inducible Cre expression. Alcian blue staining at the base of crypts, was much weaker in Tak $1^{\mathrm{IE}-\mathrm{IKO}}$ $\mathrm{Tnfr}^{-1-}$ at day 4 after tamoxifen injection (Figure 2a; upper panels). Goblet cells (strong Alcian blue-positive cells) were decreased but still observable at day 7 after tamoxifen injection (Figure 2a; lower panels). Thus, both Paneth and goblet cells seem to be sensitive to Tak1 deletion, but the impact of Tak1 deletion is more profound in Paneth cells. Overall intestinal architecture (villi and crypts) was largely intact (see Figure 2a, bottom panels), but cell alignment in the Tak1 ${ }^{\mathrm{IE}-\mathrm{IKO}} \mathrm{Tnfr}^{-/}$crypt was disorganized (Figure 1c). Whereas proliferating cells were similarly detected in both control and Tak1-deficient crypts, proliferating cells were occasionally found outside the normal transient-amplifying cell area such as in the base of crypt in Tak $1^{\mathrm{IE}-\mathrm{IKO}} \mathrm{Tnfr}^{-/-}$ crypt (Figure 2b). We note here that, as Tak1 deficiency mainly induces cell death within the area where proliferative cells reside as shown later, ectopic cell proliferation may be due to cell death-induced compensatory proliferation. In contrast to the small intestine, the colon was found to be relatively intact in Tak1 ${ }^{\mathrm{IE}-\mathrm{IKO}} \mathrm{Tnfr}^{-1}{ }^{--}$mice even after 2 months (Supplementary Figure S1E). Collectively, Tak1 deficiency predominantly affects Paneth cell integrity and cell alignment in the small intestinal crypts.

Paneth cell loss was observed around day 7 , which is much shorter than the lifespan of Paneth cells. Thus, the cause of Paneth cell depletion should not be due to impairment in the renewal processes but should be due to premature removal (cell death) of pre-existing Paneth cells. Indeed, we observed morphologically disrupted Paneth cells in Tak1 ${ }^{\mathrm{IE}-\mathrm{IKO}} \mathrm{Tnfr}^{-/-}$ crypt at day 4 (Figure 1c, top right panel, arrows). These results suggest that Tak1 deletion induces Paneth cell depletion, which is likely to be caused by Paneth cell death.

Gut bacteria are the cause of accumulation of ROS in the Tak1-deficient intestinal epithelium. Intestinal epithelialspecific Tak1 deficiency induces ROS accumulation and cell death. ${ }^{3}$ We assessed ROS by using a general peroxide detection agent, $\mathrm{CM}-\mathrm{H}_{2}$ DCFDA, which is converted to a fluorescent product by cellular peroxides and is trapped inside of the cells. ${ }^{22}$ Earlier studies have shown that CM$\mathrm{H}_{2}$ DCFDA staining is capable of detecting ROS in tissue sections of the intestine ${ }^{3}$ and in the endothelium ${ }^{23}$ when fresh unfixed tissue sections are used. ROS-positive signals were validated by their disappearance when treated with the ROS scavenger, butylated hydroxyanisole as shown previously. ${ }^{3}$ We show that a number of cells were stained positive in Tak1 ${ }^{\mathrm{IE}-\mathrm{IKO}} \mathrm{Tnfr}^{-1-}$ intestinal epithelium, whereas almost no cells were positive in Tak1 intact controls (Figures $3 a$ and b). $\mathrm{CM}-\mathrm{H}_{2}$ DCFDA staining-positive cells had unusual morphology compared with adjacent staining-negative intestinal epithelial cells (Figure 3a). Those are typically round and 
a
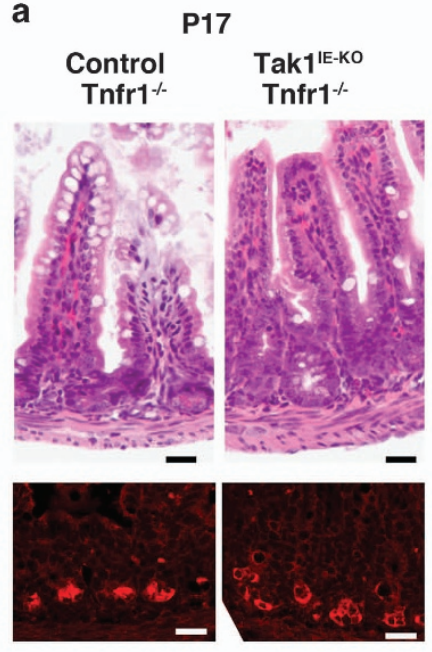

C

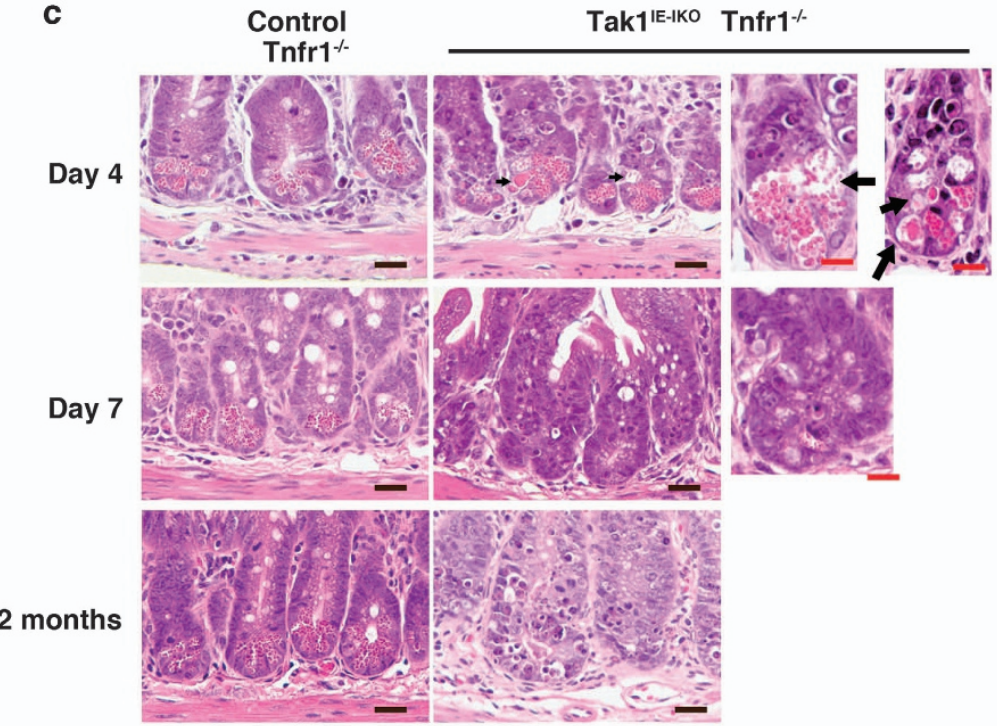

3 months old

Tnfr1 $1^{-1}$

b

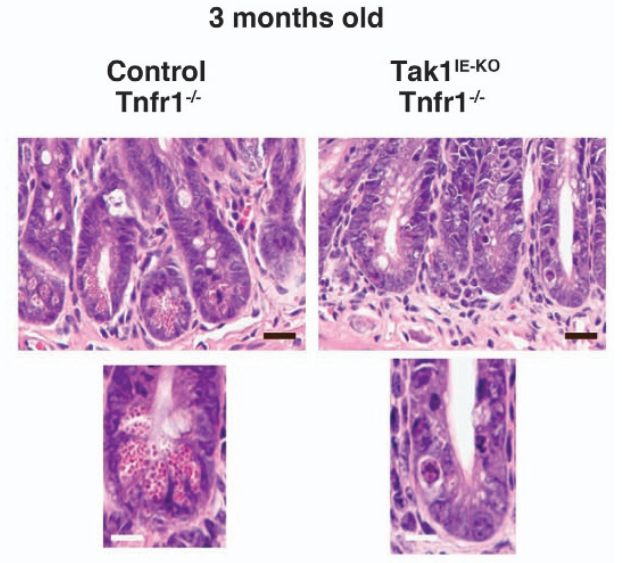

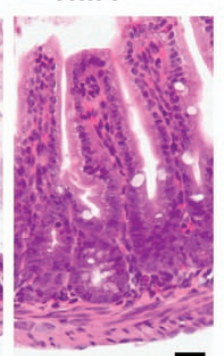



no-Cre Tnfr1 $1^{-/-} \quad$ Tak1 $^{\mathrm{IE}-\mathrm{IKO}}$ Tnfr $^{-1-}$

Day 4
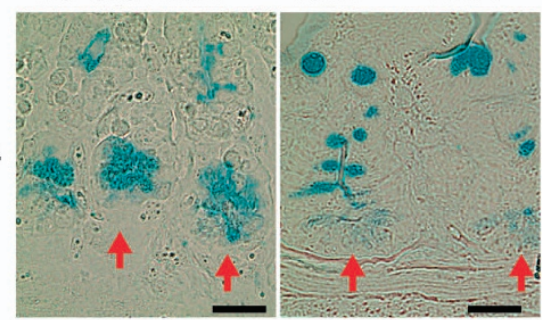

Day 7

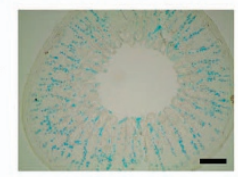

b
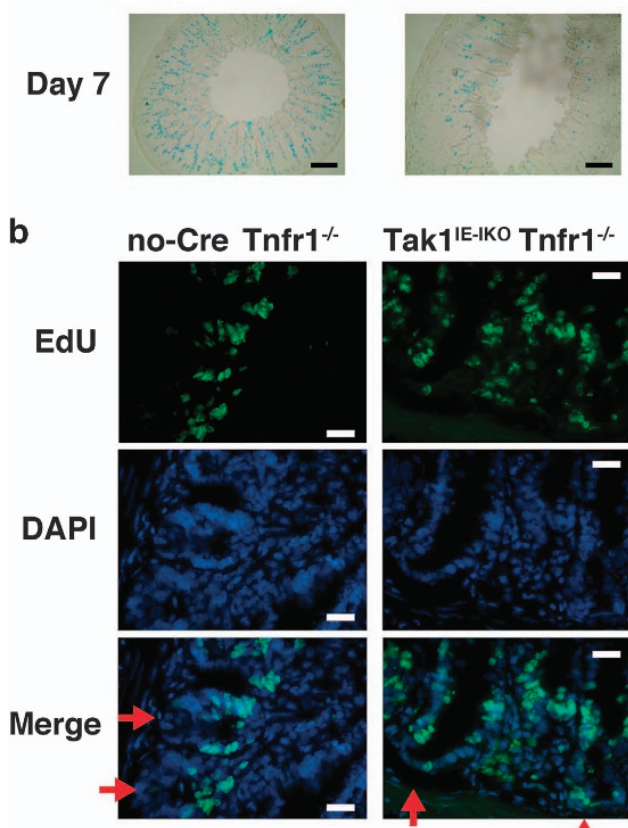

Tak1 ${ }^{\mathrm{IE}-\mathrm{IKO}}$ Tnfr1 $^{-}$
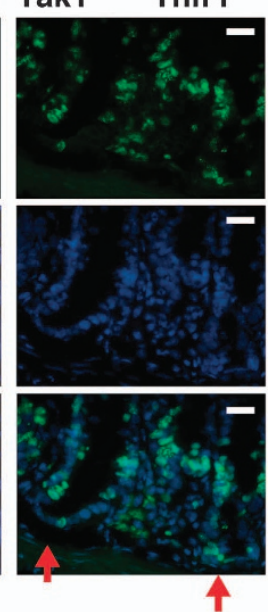

Figure 2 Tak1 deletion depletes Paneth cells without altering cell proliferation. (a) Alcian blue staining of no-Cre $\mathrm{Tnfr}^{-/-}$and Tak $1^{1 \mathrm{E}-\mathrm{KKO}} \mathrm{Tnfr}^{-1-}$ at day 3 (upper panels) or 7 (lower panels) after tamoxifen injection. To visualize weak staining of Alcian blue, no counterstaining was performed. Goblet cells were observed in lower magnification images (lower panels). Red arrows indicate the bottom of crypts. Scale bars, $50 \mu \mathrm{m}$ (upper panels); $200 \mu \mathrm{m}$ (lower panels). (b) No-Cre Tnfr $1^{-1-}$ and Tak $1^{\mathrm{E}-\mathrm{KKO}} \mathrm{Tnfr}^{-/-}$at day 14 after tamoxifen injection were treated with EdU for $4 \mathrm{~h}$. EdU and DAPI staining are shown. Scale bars, $50 \mu \mathrm{m}$. Red arrows indicate the bottom of crypts

Cleaved caspase-3-positive cells were also increased in the Tak1 ${ }^{\mathrm{IE}-\mathrm{IKO}} \mathrm{Tnfr}^{-1-}$ intestinal epithelium, which were reduced by antibiotic treatment (Supplementary Figures S2B and $\mathrm{S} 2 \mathrm{C}$ ). These results suggest that commensal bacteria are one of the major causes of ROS accumulation and cell death in the Tak1-deficient intestinal epithelium.

TLR-MyD88 pathway mediates ROS accumulation. Bacterial moieties are known to induce the production of ROS in host cells through TLR pathway. ${ }^{24}$ TLRs activate NADPH oxidases and also upregulate mitochondrial ROS production. ${ }^{26-28}$ We asked whether TLR signaling is responsible for ROS accumulation in the Tak1-deficient intestinal epithelium. TLR signaling pathways are mediated through two key adaptor proteins, that is, myeloid differentiation factor 88 (MyD88) and TIR-domain-containing adapter-inducing interferon- $\beta$ (TRIF). ${ }^{29}$ Among them, TLR-MyD88 pathway is implicated in the activation of ROS production. ${ }^{26,27}$ To test the involvement of TLR-MyD88 signaling in Tak1 deficiencyinduced ROS, we utilized the inducible Myd88-deficient system. ${ }^{30}$ We generated mice harboring compound inducible deletion of Tak1 and Myd88 on a background of Tnfr1 ${ }^{-/-}$ $\left(T a k 1^{\mathrm{IE}-\mathrm{IKO}}\right.$, Myd88 $\left.^{\mathrm{IE}-\mathrm{IKO}} \mathrm{Tnfr}^{-/-}\right)$. Myd88 mRNAs in the small intestine were reduced after tamoxifen injection (Supplementary Figure S3A). We examined ROS levels in Tak1 ${ }^{\mathrm{IE}-\mathrm{IKO}}$, Myd88 ${ }^{\mathrm{IE}-\mathrm{IKO}} \mathrm{Tnfr}^{-/-}$and Myd88 heterozygous inducible deletion littermate (Tak1 ${ }^{\mathrm{IE}-\mathrm{IKO}}$, Myd88 ${ }^{\mathrm{Het}} \mathrm{Tnfr}^{-/-}$) mice. Myd88 heterozygous intestinal epithelium exhibited increased ROS similar to Tak1 single-deficient intestinal epithelium (Figure 4b), but homozygous deletion of Myd88 alleviated the accumulation of ROS (Figures $4 a$ and b). TUNEL-positive and cleaved caspase-3-positive cells were also decreased but not completely diminished in Tak $1^{\mathrm{IE}-\mathrm{IKO}}$, Myd88 ${ }^{\mathrm{IE}-\mathrm{IKO}} \mathrm{Tnfr}^{-1-}$ mice (Figures $4 \mathrm{c}$ and $\mathrm{d}$, and Supplementary Figures S3B and S3C). Thus, Myd88 deletion resembles the antibiotic treatment, suggesting that commensal bacteria-induced TLR-MyD88 signaling is one of the major pathways to induce excessive ROS accumulation in the Tak1-deficient intestinal epithelium. We note here that this partial prevention of ROS accumulation by antibiotic treatment or Myd88 deletion only marginally improved intestinal injury (Supplementary Figures S2D and S3D), suggesting that additional mechanisms are also involved in tissue injury in the Tak1-deficient intestinal epithelium.

Paneth cell loss is independent of gut bacteria or MyD88. If highly accumulated ROS are the cause of Paneth cell loss, antibiotic treatment or Myd88 deletion should block loss of Paneth cells in the Tak1-deficient intestinal epithelium. However, hematoxylin and eosin (H\&E) staining revealed that granulated cells in the base of crypt were still not observed in the antibiotic-treated Tak $1^{\mathrm{IE}-\mathrm{IKO}} \mathrm{Tnfr}^{-/}{ }^{-/}$intestinal epithelium (Figure 5a). We counted the number of Paneth cells in each crypt by using the Paneth cell marker, lysozyme, which we could clearly detect and visualize individual Paneth cells (see Supplementary Figure S1A). Only a few crypt base cells were detected as positive for lysozyme in Tak1 $1^{\mathrm{IE}-\mathrm{IKO}} \mathrm{Tnfr}^{-/}$ (Figures $5 b$ and c). Similarly, Paneth cells were not increased in Tak1 ${ }^{\mathrm{IE}-\mathrm{IKO}}$ Myd88 ${ }^{\mathrm{IE}-\mathrm{IKO}} \mathrm{Tnfr}^{-/-}$intestinal crypts compared with Myd88 heterozygous deletion mice (Figures $5 \mathrm{~d}-\mathrm{f}$ ). We have previously reported that treatment with a ROS scavenger, butylated hydroxyanisole, can diminish ROSpositive cells and reduces cell death in the Tak1 $1^{\mathrm{IE}-\mathrm{IKO}}$ Tnfr $^{-1-}$ intestinal epithelium. ${ }^{3}$ However, Paneth cell loss was still observed in the butylated hydroxyanisole-treated Tak1 $1^{\mathrm{IE}-\mathrm{IKO}} \mathrm{Tnfr}^{-/}$intestine (Supplementary Figure S4A). Thus, accumulated ROS are not the cause of Paneth cell loss in the Tak1-deficient intestinal epithelium. These results suggest that commensal bacteria are causally involved in increased ROS in the Tak1-deficient intestinal epithelium, whereas Paneth cells are depleted through a bacteria-ROSindependent mechanism.

RIPK3-dependent cell death is involved in Paneth cell loss and is the cause of ROS accumulation. Our results above demonstrate that Paneth cell depletion is not due to bacteria-induced ROS. However, Paneth cells were depleted 
within a period shorter than their normal life span, and Tak1 deletion structurally disrupts Paneth cells (see Figure 1c). Thus, the cause of Paneth cell loss is still likely due to cell death. Ablation of Tak1 is known to primarily induce apoptotic cell death; ${ }^{7}$ however, it is also implicated in induction of necroptosis. ${ }^{8-11}$ Intestinal epithelial-specific deletion of Tak1 could potentially induce apoptosis and/or necroptosis in Paneth cells. Interestingly, it was reported that intestinal
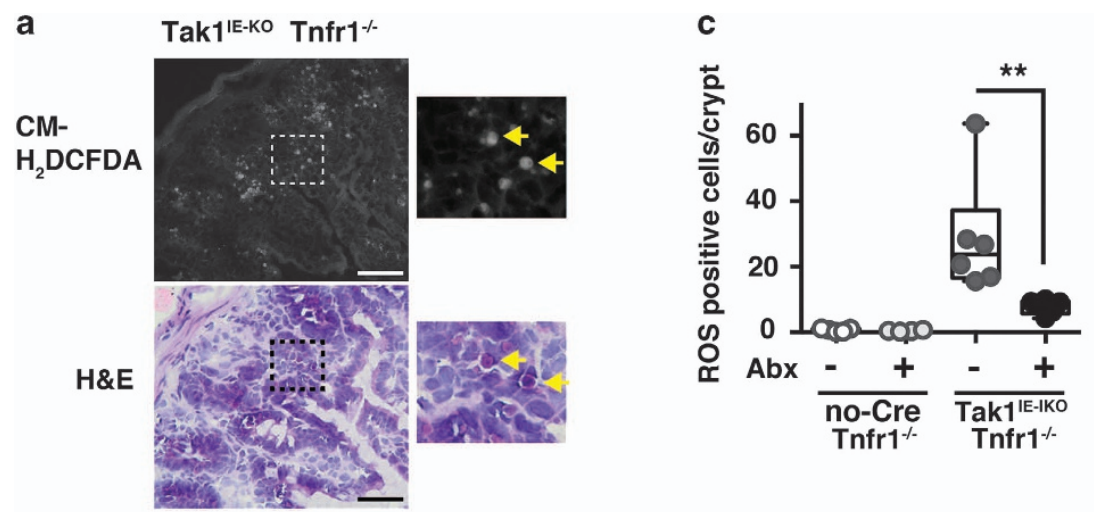

b

Abx

Abx
CM-
$\mathrm{H}_{2}$ DCFDA
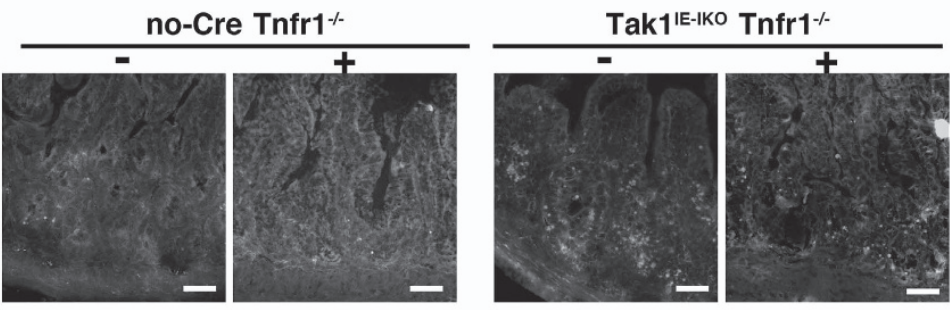

d
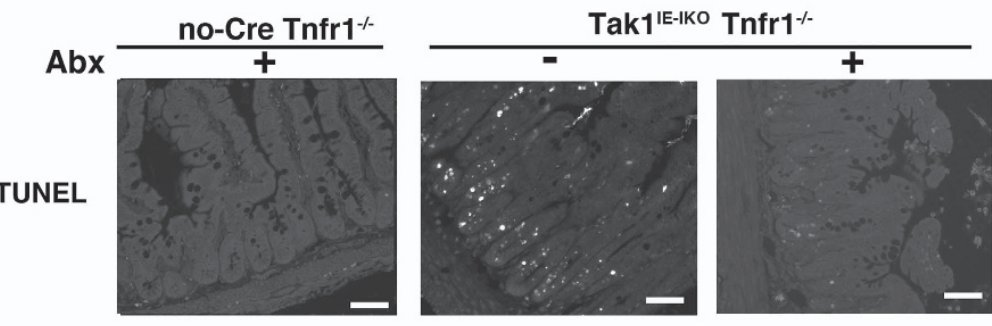

e

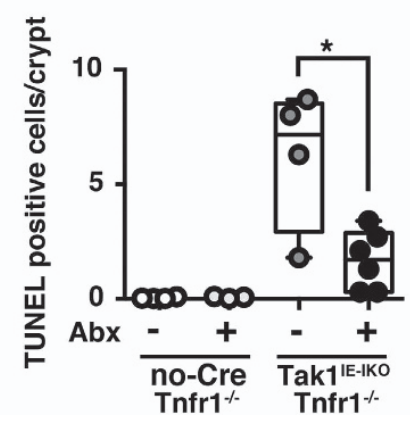

Figure 3 Antibiotic treatment reduces ROS and apoptosis. (a) ROS were determined by CM- ${ }_{2} \mathrm{DCFDA}$ staining using freshly prepared unfixed cryosections of Tak1 ${ }^{\mathrm{E}-\mathrm{IKO}}$ $\mathrm{Tnfr}^{-/-}$small intestine at day 14 after tamoxifen injection (upper panels). The section was subsequently fixed and stained by H\&E. The same position was photographed. Higher magnification (lower panel) or enlarged (upper panel) images of the dash line boxes in the right panels are shown in the left panels. Yellow arrows indicate the ROS-positive cells. Scale bars, $50 \mu \mathrm{m}$. (b) Control no-Cre Tnfr1 ${ }^{-1-}$ and Tak $1^{\mathrm{E}-\mathrm{KKO}} \mathrm{Tnfr}^{-1-}$ mice were treated with water alone or antibiotic cocktail water for 4 weeks and tamoxifen was injected once per day for three consecutive days. Days 7-10 after tamoxifen injection, fresh ileum sections were stained with CM-H $\mathrm{H}_{2} \mathrm{DCFDA}$. Scale bars, $40 \mu \mathrm{m}$. (c) ROS-positive cells in each crypt of samples in (b) were counted, and the data shown are from four to six mice of the average of ROS-positive cells in more than 100 crypts per mouse. Control Tnfr $1^{-/-}$ mice; without $(n=5)$ and with $(n=4)$ antibiotics $(\mathrm{Abx})$. Tak $1^{\mathrm{E}-\mathrm{KO}} \mathrm{Tnfr}^{-1-}$ mice; without $(n=6)$ and with $(n=6)$ antibiotics. All data points are shown in the box and whisker plots: median and distribution of $50 \%$ of values are shown in the box: whiskers indicate distribution of minimum and maximum values. ${ }^{* *} P<0.01$ (one-way ANOVA). (d) TUNEL staining. Scale bars, $50 \mu \mathrm{m}$. (e) TUNEL-positive cells were counted (more than 30 crypts per mouse). Control Tnfr1 ${ }^{-/}$mice; without $(n=4)$ and with $(n=3)$ antibiotics (Abx). Tak1 $1^{\mathbb{E}-1 K \mathrm{~K}}$ Tnfr1 ${ }^{-1-}$ mice; without $(n=4)$ and with $(n=6)$ antibiotics. All data points are shown in the box and whisker plots: median and distribution of $50 \%$ of values are shown in the box: whiskers indicate distribution of minimum and maximum values. ${ }^{*} P<0.05$ (one-way ANOVA) 
a

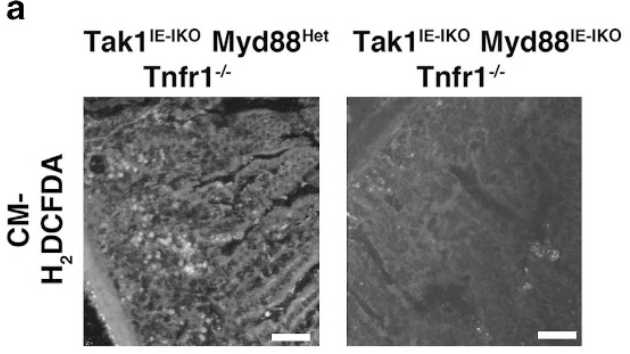

c

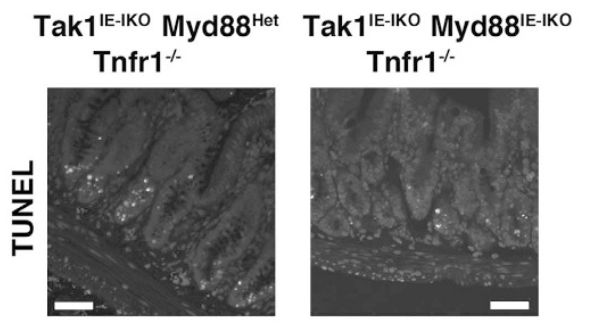

b
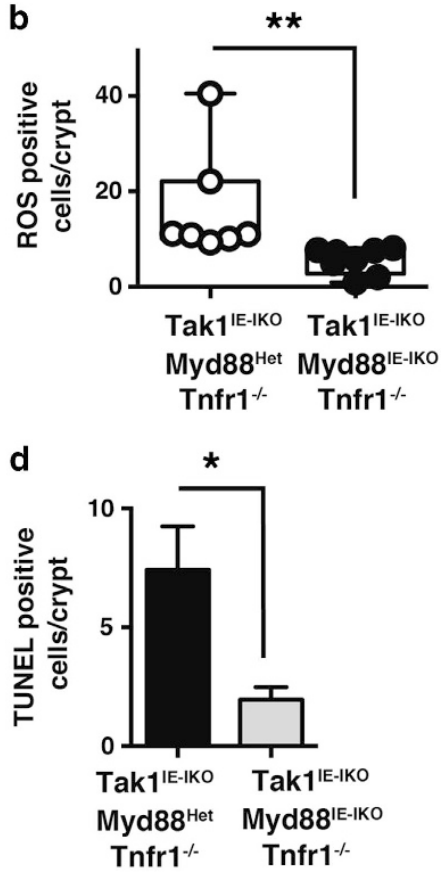

Figure 4 Myd88 deletion reduces ROS and apoptosis. (a) ROS-sensitive dye staining of Myd88 heterozygous or Myd88 homozygous deletion Tak $1^{1 \mathrm{E}-\mathrm{IKO}}$ Tnfr $1^{-/-}$ileum crypts at days 10-12 after tamoxifen injection. Scale bars, $50 \mu \mathrm{m}$. (b) ROS-positive cells in each crypt of samples in (a) were counted (more than 100 crypts per mouse). Myd88 heterozygous deletion Tak $1^{\mathrm{IE}-\mathrm{KKO}} \mathrm{Tnfr}^{-1}{ }^{--}$mice; $n=7$; Myd88 homozygous deletion Tak1 $1^{\mathrm{EE}-\mathrm{KKO}} \mathrm{Tnfr}^{-/-}$mice; $n=8$. All data points are shown in the box and whisker plots: median and distribution of $50 \%$ of values are shown in the box: whiskers indicate distribution of minimum and maximum values. ${ }^{*} P<0.01$ (two-tailed unpaired Student's $t$-test). (c) TUNEL staining. Scale bars, $50 \mu \mathrm{m}$. (d) Quantification of TUNEL-positive staining (more than $30 \mathrm{crypts}$ per mouse). Myd88 heterozygous deletion Tak1 ${ }^{\mathrm{E}-\mathrm{IKO}} \mathrm{Tnfr}^{-/-}$mice; $n=3$; Myd88 homozygous deletion Tak1 ${ }^{\mathbb{E}-1 K O}{ }^{T n f r} 1^{-/-}$mice; $n=3$. Means \pm S.E.M., ${ }^{\star} P<0.05$ (two-tailed unpaired Student's $t$-test)

epithelial-specific deletion of necroptosis inhibitors such as caspase 8 and its activator Fas-associated protein with death domain (FADD) induces Paneth cells loss. ${ }^{31,32}$ This might suggest that Paneth cells are sensitive to necroptosis. Necroptosis is morphologically indistinguishable from necrosis but characterized by a specific feature, dependency on a protein kinase, receptor interacted protein kinase 3 (RIPK3). ${ }^{33}$ RIPK3 is expressed in Paneth cells. ${ }^{31}$ To determine whether Paneth cell loss in the Tak1-deficient intestinal epithelium is caused by necroptosis, we generated intestinal epithelial-specific deletion of $\mathrm{Tak}^{\mathrm{Tnfr}} \mathrm{Tn}^{-/}$on a background of Ripk3 ${ }^{--}$mice (Tak $1^{\mathrm{IE}-\mathrm{IKO}} \mathrm{Tnfr}^{-/-} \mathrm{Ripk}^{-/-}$). We analyzed and compared the ileum of no-Cre Tnfr1 $1^{-1}$ Ripk3 $^{-/-}$(control), Tak1 ${ }^{\mathrm{IE}-\mathrm{IKO}} \mathrm{Tnfr}^{-/-} \mathrm{Ripk}^{+/+}{ }^{-/ T a k} 1^{\mathrm{IE}-\mathrm{IKO}}$ $\mathrm{Tnfr}^{-/-} \mathrm{Ripk}^{+/-}$and Tak1 ${ }^{\mathrm{IE}-\mathrm{IKO}} \mathrm{Tnfr}^{-/-} \mathrm{Ripk}^{-/-}$. Intestinal injury was still observed in Tak $1^{1 \mathrm{E}-\mathrm{KOO}} \mathrm{Tnfr}^{-/-} \mathrm{Ripk}^{-/-}$mice (Figure 6a). However, we found that Paneth cell loss was partially blocked by Ripk3 deletion (Figures $6 \mathrm{~b}$ and $\mathrm{c}$ ). These suggest that Paneth cells in the Tak1-deficient intestinal epithelium were depleted at least partially by necroptosis. Finally, we examined whether this partial restoration of Paneth cells could alleviate ROS. We found that the level of ROS was marginally decreased by deletion of Ripk3 (Figures $6 \mathrm{~d}$ and e). Although there is a trend of ROS reduction by Ripk3 deletion, no statistical significance is observed (Figure 6e). TUNEL-positive cells were not observably altered by Ripk3 deletion (Supplementary Figures S4B and $C$ ). This suggests that most of cell the death observed in the Tak1-deficient intestinal epithelium is not dependent on RIPK3 but Paneth cell loss is selectively associated with this form of cell death. Collectively, TAK1 regulates Paneth cell loss and bacteria-induced ROS accumulation through two independent mechanisms. However, the moderate reduction of ROS by deletion of Ripk3 suggests the possibility that Paneth cell loss is in part causally associated with ROS accumulation.

\section{Discussion}

Paneth cells are unique epithelial cells in the small intestine, which are raised from intestinal epithelial stem cells as are other intestinal epithelial cell types but migrate downward while all other cell types migrate upwards. Paneth cells are specialized to secrete antimicrobial peptides and enzymes to control microbiota in the small intestinal crypts. Paneth cells are also visually unique in histological analysis, in which eosinophilic large granules occupy most of the cytoplasm. Destruction of Paneth cells is often histologically observed in ileitis from patients having one type of IBD, Crohn's disease. ${ }^{18,19}$ Given their importance in gut microbiota homeostasis, disrupted Paneth cells are likely to be causally associated with ileitis. Indeed, Paneth cell loss has recently been implicated in the initiation of intestinal inflammation. ${ }^{34}$ Thus, determination of the mechanism of how Paneth cells are maintained is important for better understanding of IBD pathology and treatment. Paneth cell loss has been reported 
a no-Cre Tnfr1 ${ }^{-1}$ Tak1 ${ }^{1 E-1 K O}$ Tnfr1 $^{-\%}$

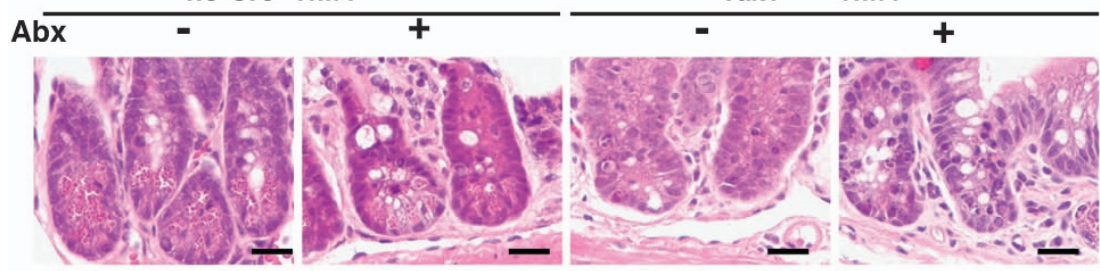

b

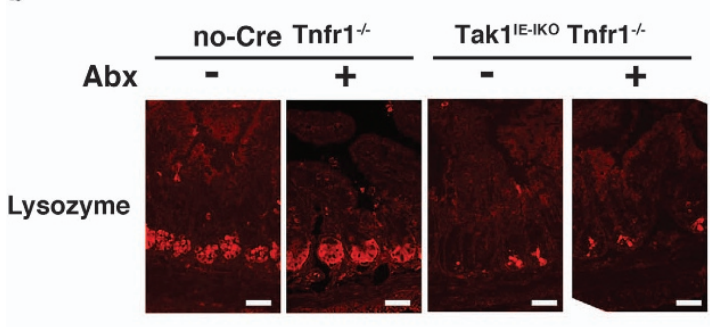

d

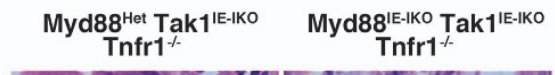

c

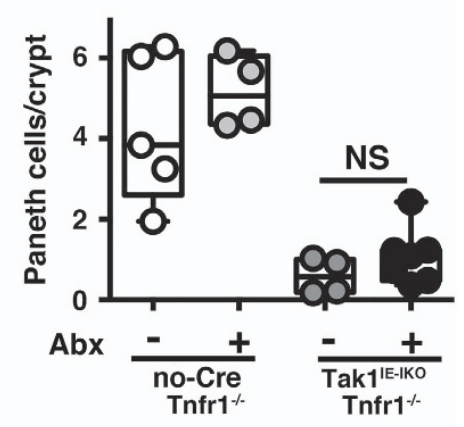

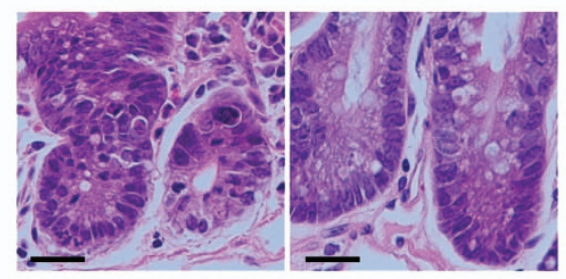

e

Myd88 $^{\text {Het }}$ Tak1 ${ }^{\mathrm{IE}-\mathrm{IKO}}$ Myd88 ${ }^{\mathrm{IE}-\mathrm{IKO}}$ Tak1 ${ }^{\mathrm{IE}-\mathrm{IKO}}$
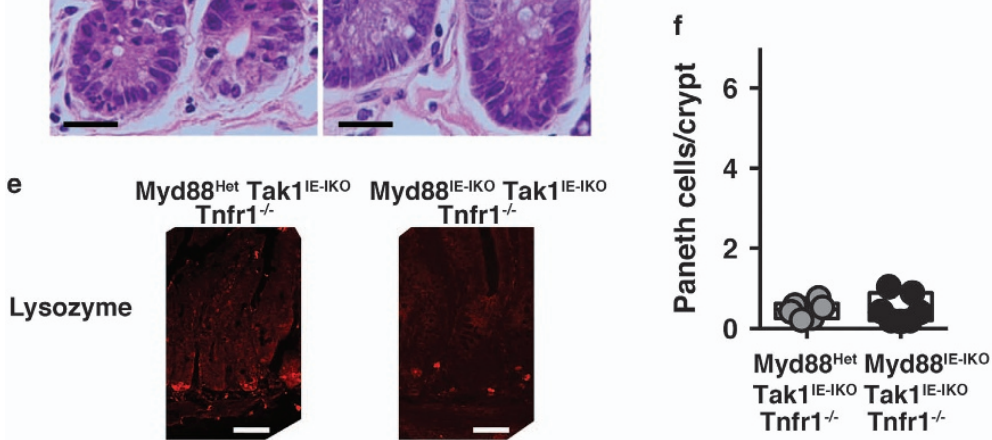

Figure 5 Antibiotic treatment or Myd88 deletion does not block Paneth cell loss. (a) H\&E staining and (b) immunofluorescence staining of lysozyme in the crypts of ileum with and without antibiotic treatment at days 7-10 after tamoxifen injection. Scale bars, (a) $20 \mu \mathrm{m}$; (b) $40 \mu \mathrm{m}$. (c) Quantification of lysozyme staining-positive cells. More than 100 crypts per mouse were counted. Control Tnfr1 ${ }^{-/}$mice; without $(n=5)$ and with $(n=5)$ antibiotics. Tak1 ${ }^{1 E-1 K O}$ Tnfr1 $^{-/-}$mice; without $(n=4)$ and with $(n=7)$ antibiotics. All data points are shown in the box and whisker plots: median and distribution of $50 \%$ of values are shown in the box: whiskers indicate distribution of minimum and maximum values. NS, not significant (one-way ANOVA). (d) H\&E staining and (e) immunofluorescence staining of lysozyme of Myd88 heterozygous or Myd88 homozygous deletion Tak1 $1^{\mathrm{E}-\mathrm{KKO}} \mathrm{Tnfr}^{-/-}$ ileum crypts at days 10-12 after tamoxifen injection. Scale bars, (d) $20 \mu \mathrm{m}$; (e) $50 \mu \mathrm{m}$. (f) Quantification of (e) (more than 100 crypts per mouse). Myd88 heterozygous deletion Tak1 ${ }^{1 \mathrm{E}-1 \mathrm{KO}} \mathrm{Tnfr}^{--}$mice; $n=6$; Myd88 homozygous deletion Tak $1^{\mathrm{IE}-\mathrm{KKO}} \mathrm{Tnfr}^{-/-}$mice; $n=7$. All data points are shown in the box and whisker plots: median and distribution of $50 \%$ of values are shown in the box: whiskers indicate distribution of minimum and maximum values. NS, not significant (one-way ANOVA)

in several genetically engineered mouse models. Most intriguingly, intestinal epithelium-specific deletion of caspase 8 or its activator, Fadd, which are inhibitors of necroptosis, depletes Paneth cells. ${ }^{31,32}$ This loss of Paneth cells is rescued by deletion of necroptosis mediator, Ripk3. Furthermore, RIPK3 is increased in the intestine of IBD patient samples. ${ }^{31}$ Thus, activation of necroptosis is likely to be one of the causes of pathological Paneth cell loss. However, the pathway of how necroptosis is activated in the intestinal epithelium is not clear. Our current study reveals that TAK1 is required for the prevention of Paneth cell death. As this cell death is partially prevented by deletion of a necroptosis mediator Ripk3, Tak1 deletion causes Paneth loss in part through induction of necroptosis. TAK1 is a protein kinase mediating inflammatory intracellular signaling pathways leading to NF- $K \mathrm{~B}$ and $\mathrm{AP}-1$, which is activated by a variety of inflammatory stimuli including TNF, IL-1 and Toll-like receptor ligands. In these signaling pathways, another protein kinase RIPK1 is ubiquitilyated, which serves as a scaffold of signaling molecules including TAK1. ${ }^{35}$ Both RIPK1 and TAK1 are essential molecules in these inflammatory signal transduction pathways. Recently, intestinal epithelial-specific deletion of Ripk1 was reported to deplete Paneth cells. ${ }^{36,37}$ Thus, deletion of either Tak1 or Ripk1 results in Paneth cell loss. This raises the possibility that impairment of inflammatory signaling causes Paneth cell loss. Given that intestinal epithelium is constantly exposed to gut bacteria and immune cell-derived cytokines, it may not be surprising that proper inflammatory signaling from bacteria and cytokines is involved in the maintenance of Paneth cells. Homeostatic intestinal inflammatory signaling may be one of 


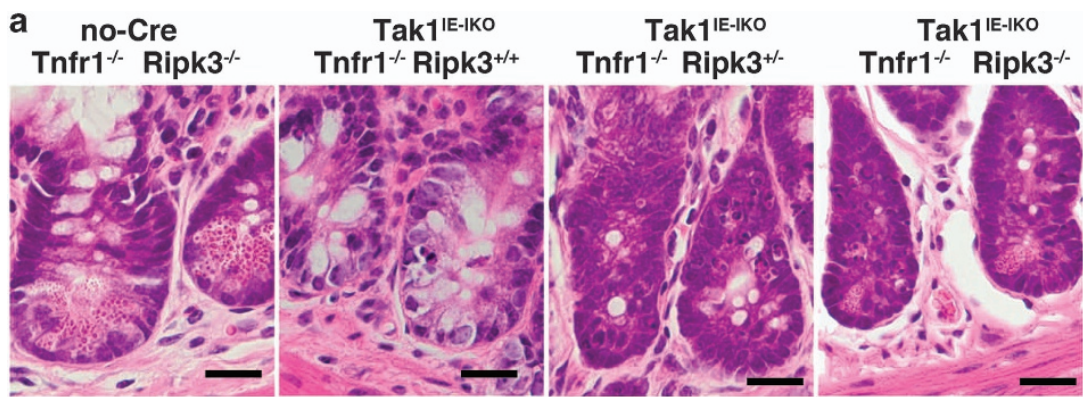

b
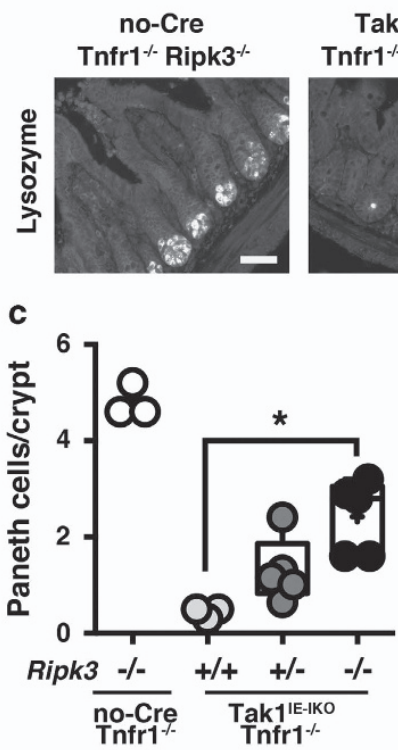

d

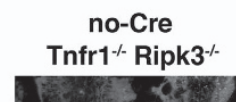

Tak1 1E-IKo Tnfr1 ${ }^{-/-}$Ripk3+/+

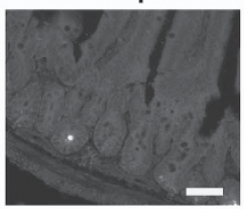

Tak1 1E-IKo Tnfr1\% Ripk3 ${ }^{\text {+/- }}$

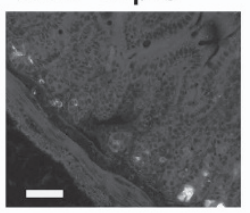

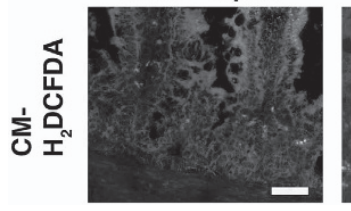

Tak1 ${ }^{\mathrm{IE}-\mathrm{IKO}}$ Tnfr1 ${ }^{-/}$Ripk3 $3^{+/+}$
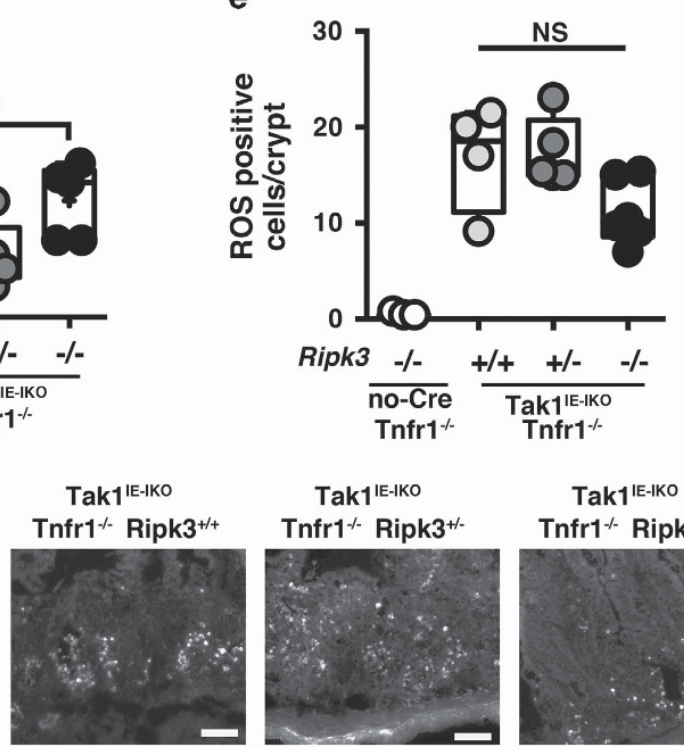

Tak $1^{\text {IE-IKo }}$ Tnfr1 ${ }^{--}$Ripk3 ${ }^{+-}$

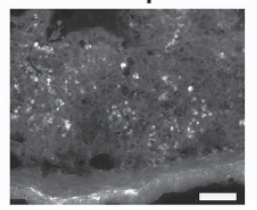

Tak1 $1^{\mathrm{IE}-\mathrm{IKO}}$ Tnfr1 ${ }^{-2}$ Ripk3 ${ }^{-}$

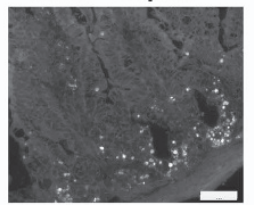

Figure 6 Ripk3 deletion partially rescues Paneth cells loss and marginally reduces ROS accumulation. (a) H\&E staining and (b) immunofluorescence staining of lysozyme of the indicated mouse genotype ileum crypts at day 14 after tamoxifen injection. Scale bars, (a) $20 \mu \mathrm{m}$; (b) $50 \mu \mathrm{m}$. (c) Quantification of (b) (more than 50 crypts per mouse). no-Cre

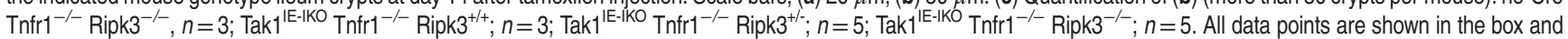
whisker plots: median and distribution of $50 \%$ of values are shown in the box: whiskers indicate distribution of minimum and maximum values. ${ }^{*} P<0.05$ (one-way ANOVA). (d) ROS dye staining of the ileum crypts at day 14 after tamoxifen injection. Scale bars, $50 \mu \mathrm{m}$. (e) Quantification of (d) (more than 30 crypts per mouse). no-Cre Tnfr1 ${ }^{-1-}$ Ripk3 $^{-/-}, n=3$; Tak1 ${ }^{\mathrm{E}-\mathrm{IKO}} \mathrm{Tnfr}^{-/-} \mathrm{Ripk}^{+/+} ; n=4$; Tak1 ${ }^{\mathrm{E}-\mathrm{IKO}} \mathrm{Tnfr}^{-/-} \mathrm{Ripk}^{+/-} ; n=6 ;$ Tak1 $^{\mathrm{E}-\mathrm{IKO}} \mathrm{Tnfr}^{-/-}$Ripk3 $^{-/-} ; n=5$. All data points are shown in the box and whisker plots: median and distribution of $50 \%$ of values are shown in the box: whiskers indicate distribution of minimum and maximum values. NS, not significant (one-way ANOVA)

the key factors to maintain Paneth cells through preventing RIPK3-dependent necroptosis.

In the Tak1-deficient intestinal epithelium, ROS are highly accumulated and the intestinal epithelium is severely damaged. Our results demonstrate that gut bacteria cause ROS accumulation in the Tak1-deficient intestinal epithelium. Because inhibition of Paneth cell loss slightly reduces ROS accumulation in the Tak1-deficient intestinal epithelium, Paneth cell loss may disrupt normal commensal microbiota, which may be involved in ROS accumulation. However, ROS accumulation and cell death in the Tak1-deficient intestinal epithelium seem to be much more pronounced compared with other genetically engineered mouse models harboring Paneth cell depletion. For example, caspase 8 or Fadd deletion gradually induces ileitis in a non-inducible version of intestinal epithelium-specific gene deletion system, ${ }^{31,32}$ whereas the same deletion system causes severe tissue damage and neonatal lethality when Tak 1 is deleted. ${ }^{13}$ This suggests that additional mechanisms are involved in the ROS-induced tissue injury by Tak1 deletion. Tak1 deletion has been shown to reduce the capacity of cellular antioxidant systems through downregulation of antioxidant transcription factors such as 
NF- $k$ B, AP-1 and Nrf2. ${ }^{3,5}$ We previously showed that Tak1 deletion downregulates the levels of Nrf2 and its target antioxidant enzyme, (NAD(P)H dehydrogenase 1 (NQO1). ${ }^{3}$ Thus, the impaired antioxidant system may contribute to the high accumulation of ROS in the Tak1-deficient intestinal epithelium. Our results collectively demonstrate that basal activity of TAK1 in the normal intestine is critical in intestinal homeostasis by preventing Paneth cell loss and unattended accumulation of bacteria-induced ROS.

\section{Materials and Methods}

Mice. Mice carrying a floxed Map3k7 allele $\left(T a k t^{f / / f}\right)^{38}$ were backcrossed to C57BL/6 mice for at least seven generations. Tnfr1-deficient $\left(\right.$ Tnfr $\left.^{-1-}\right),{ }^{39}$ Myd88floxed $\left(M y d 88^{f / f / f}\right)^{30}$ and an intestinal epithelium-specific deleter (villin.Cre) ${ }^{40}$ mice with a C57BL/6 background were from The Jackson Laboratory. The inducible intestinal epithelium-specific deleter (villin.CreER ${ }^{T 2}$ ) (a gift from Dr. Robine) ${ }^{41}$ and Ripk3-deficient $\left(\right.$ Ripk3 ${ }^{-1-}$ ) (a gift from Dr. Dixit) ${ }^{42}$ were also used. We generated constitutive and inducible versions of intestinal epithelium-specific Tak1 (villin.Cre

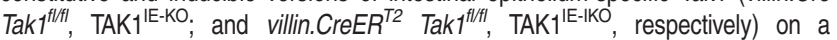

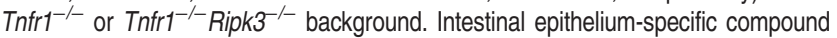
deletion of Tak1 and Myd88 (villin.CreER ${ }^{T 2}$ Tak $1^{f / f \mid} M y d 88^{f / f / I}$, TAK1 Myd88 $8^{\mid \mathrm{E}-\mathrm{IKO}}$ ) mice were generated on a Tnfr1 ${ }^{-/}$background. Littermate control mice (no-Cre

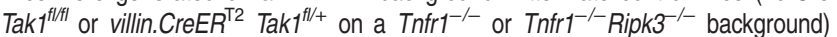
were included in all experiments, but some other litter control mice were also used. All control (Tak1 wild-type or heterozygous deletion) mice exhibited no ROS accumulation and four to six Paneth cells were observed in each crypt. To induce gene deletion, 6-12- week-old mice were given intraperitoneal injections of tamoxifen ( $1 \mathrm{mg}$ per mouse, approximately $20 \mathrm{~g}$ body weight, per day) for three to five consecutive days. The first day of tamoxifen injection is herein referred to as day 1. For antibiotic treatment, the antibiotic cocktail consisting of ampicillin $(1 \mathrm{~g} / /)$, vancomycin $(0.5 \mathrm{~g} / \mathrm{l})$, neomycin sulfate $(1 \mathrm{~g} / \mathrm{l})$ and metronidazole $(1 \mathrm{~g} /)^{25}$ was added to the drinking water of 6-8 week-old mice for 4 weeks prior to the tamoxifen injected. The antibiotic treatment was continued during and after the tamoxifen injection until the end of experiments. Mice were maintained in ventilated cages at the specific pathogen-free animal facility and fed regular chow diet. All animal experiments were conducted with the approval of the North Carolina State University Institutional Animal Care and Use Committee. All efforts were made to minimize animal suffering.

Histology and immunofluorescence staining. For H\&E staining, a part of ileum was fixed in $4 \%$ paraformaldehyde and embedded into paraffin, and cross sections were stained by H\&E. Sections are scored in a blinded manner on the scale from 0 to 4 , based on the degree of lamina propria mononuclear cell infiltration, crypt hyperplasia, goblet cell depletion and architectural distortion described previously. ${ }^{13,43}$ To detect intestinal ROS, ileums were embedded optimum cutting temperature compound and frozen immediately. Cryosections $(8 \mu \mathrm{m})$ were incubated with the ROS staining dye $\left(\mathrm{CM}-\mathrm{H}_{2} \mathrm{DCFDA}\right.$, Life Technologies, Waltham, MA, USA) for $30 \mathrm{~min}$ at room temperature. To detect cell death, paraffin-embedded sections were used for DeadEnd Fluorometric TUNEL staining (Promega, Madison, WI, USA). To detect Paneth cells, immunofluorescence staining of lysozyme and Alcian blue staining were performed. For immunofluorescence staining of lysozyme, $4 \%$ paraformaldehyde-fixed paraffin sections were rehydrated, heat-induced antigen retrieval was performed in a citrate buffer (10 mM citric acid, $0.05 \%$ Tween 20, pH 6.0 ), and the sections were stained using the muramidase (lysozyme) primary antibody (1:200, Novocastra, Leica, Buffalo Grove, IL, USA) overnight at $4{ }^{\circ} \mathrm{C}$. Bound antibodies were visualized by the Alexa Fluor 594 fluorescence dyeconjugated secondary antibody. Paraffin-embedded sections fixed with $4 \%$ paraformaldehyde were used for Alcian blue staining. Some sections were counterstained with Schiffs reagent. To determine cell proliferation, thymidine analog, 5-ethynyl-2'-deoxyuridine (EdU) (1 mg per mouse) was injected $4 \mathrm{~h}$ prior to euthanasia, cryosections fixed with $4 \%$ paraformaldehyde were prepared. EdU incorporation was visualized by Click-iT EdU Alexa Fluor 488 Imaging Kit (Life Technologies). For immunofluorescence staining of cleaved caspase 3 , cryosections fixed with $4 \%$ paraformaldehyde were incubated with primary antibodies against cleaved caspase 3 (Asp175, 1:200, Cell Signaling, Danvers, MA, USA). Bound antibodies were visualized by the Alexa Fluor 488 fluorescence dye-conjugated secondary antibody (1:1000, Life Technologies). Nuclei were counterstained with
DAPI. Images were visualized using a fluorescent microscope (BX41; Olympus, Waltham, MA, USA) controlled by the CellSens imaging software (Olympus). Random portions of the intestine were selected and images were visualized and photographed using the same exposure times. To quantify the positive stained cells, we pick five to six areas from more than three different cross sections per animal, and counted cells in each crypt. Any non-specific stainings that did not have nuclear DAPI staining were removed.

Immunoblotting analysis of intestinal epithelial cells. The small intestine was harvested and flushed with phosphate buffer saline. One end of the intestine was tied off, filled with Hanks' Balanced Salt Solution (HBSS, Sigma, St. Louis, MO, USA) containing $10 \mathrm{mM}$ EDTA and incubated in a phosphate buffer saline bath at $37^{\circ} \mathrm{C}$ for $5-10 \mathrm{~min}$. The contents (intestinal epithelial cells) were collected and lysed in a cell extraction buffer containing $20 \mathrm{mM}$ HEPES (pH 7.4), $150 \mathrm{mM} \mathrm{NaCl}, 12.5 \mathrm{mM} \beta$-glycerophosphate, $1.5 \mathrm{mM} \mathrm{MgCl} 2,2 \mathrm{mM}$ EGTA, $10 \mathrm{mM}$ $\mathrm{NaF}, 2 \mathrm{mM}$ DTT, $1 \mathrm{mM}$ Na3VO4, $1 \mathrm{mM}$ phenylmethylsulfonyl fluoride, $20 \mu \mathrm{M}$ aprotinin and $0.5 \%$ Triton $X-100$. Proteins were electrophoresed on SDS-PAGE and transferred to Hypond-P membranes (GE Healthcare, Pittsburgh, PA, USA). The membranes were immunoblotted with anti-TAK1 ${ }^{44}$ and $\beta$-actin (AC-15, Sigma), and the bound antibodies were visualized with horseradish peroxidase-conjugated antibodies against rabbit or mouse IgG using the ECL Western blotting system (GE Healthcare).

mRNA and bacteria DNA detection by real-time PCR. RNA was isolated by using RNeasy Kit (Qiagen), and Myd88 mRNA was determined by realtime PCR. Feces bacterial DNA was isolated using QIAamp DNA Stool Mini Kit (Qiagen, Valencia, CA, USA) and purified DNAs were analyzed by using two different bacterial ribosome $S 16$ universal primers ${ }^{45,46}$ and a primer set for Bacteroidetes. ${ }^{46}$ Primers used were Myd88, 5'-CACCTGTGTCTGGTCCATT-3'; $5^{\prime}$ AGGCTGAGTGCAAACTTG-3':47 ribosome S16 universal-1, 5'-ACTCCTAC GGGAGGCAGCAG-3'; 5'-ATTACCGCGGCTGCTGG-3': ribosome S16 universal2, 5'-GTGSTGCAYGGYTGTCGTCA-3'; 5'-ACGTCRTCCMCACCTTCCTC-3': Bacteroidetes, 5'-GGARCATGTGGTTTAATTCGATGAT-3'; 5'-AGCTGACGACAACCAT GCAG-3'. mRNA levels were normalized to Gapdh mRNA. Primers for Gapdh, 5'-GAAGGTCGCTGTGAACGGA-3'; 5'-GTTAGTGGGGTCTCGCTCCT-3'. Bacterial DNA levels were normalized to feces weight.

Statistical analysis. All experiments were conducted using at least three mice and the results are confirmed by at least three separately performed experiments. The box plots show medians (line), lower and upper quartiles (boxes), 10th and 90th percentiles (whiskers) and outliers. The column graphs represent the mean \pm the standard deviation. Differences between experimental groups were assessed for significance by using the one-way ANOVA with Tukey's multiple comparisons test or the unpaired Students $t$-test (two-tailed) with equal distributions.

\section{Conflict of Interest}

The authors declare no conflict of interest.

Acknowledgements. We thank Dr. Akira for Tak1-floxed mice, Dr. Robine for

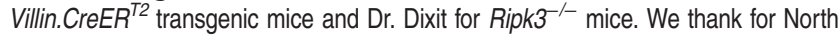
Carolina State University Histology Laboratory for preparation of paraffin sections and Biological Resources Facility for animal care. This work was supported by National Institutes of Health Grants GM068812 and GM112986 (to JN-T).

\section{Author contributions}

AS, RK and JN-T designed and performed the experiments, analyzed data and wrote the manuscript.

1. Mihaly SR, Ninomiya-Tsuji J, Morioka S. TAK1 control of cell death. Cell Death Differ 2014; 21: $1667-1676$.

2. Sen CK, Packer L. Antioxidant and redox regulation of gene transcription. FASEB J 1996; 10: 709-720.

3. Kajino-Sakamoto R, Omori E, Nighot PK, Blikslager AT, Matsumoto K, Ninomiya-Tsuji J. TGF-beta-activated kinase 1 signaling maintains intestinal integrity by preventing accumulation of reactive oxygen species in the intestinal epithelium. $J$ Immunol 2010; 185: 4729-4737.

4. Morioka S, Omori E, Kajino T, Kajino-Sakamoto R, Matsumoto K, Ninomiya-Tsuij J. TAK1 kinase determines TRAIL sensitivity by modulating reactive oxygen species and CIAP. Oncogene 2009; 28: 2257-2265. 
5. Omori E, Morioka S, Matsumoto K, Ninomiya-Tsuji J. TAK1 regulates reactive oxygen species and cell death in keratinocytes, which is essential for skin integrity. J Biol Chem 2008; 283: 26161-26168

6. Omori E, Matsumoto K, Zhu S, Smart RC, Ninomiya-Tsuji J. Ablation of TAK1 upregulates reactive oxygen species and selectively kills tumor cells. Cancer Res 2010; 70: 8417-8425.

7. Morioka S, Broglie P, Omori E, Ikeda Y, Takaesu G, Matsumoto K et al. TAK1 kinase switches cell fate from apoptosis to necrosis following TNF stimulation. J Cell Biol 2014; 204: 607-623.

8. Lamothe B, Lai Y, Xie M, Schneider MD, Darnay BG. TAK1 is essential for osteoclast differentiation and is an important modulator of cell death by apoptosis and necroptosis. Mol Cell Biol 2013; 33: 582-595.

9. Arslan SC, Scheidereit $C$. The prevalence of TNFalpha-induced necrosis over apoptosis is determined by TAK1-RIP1 interplay. PLOS ONE 2011; 6: e26069.

10. Vanlangenakker $N$, Vanden Berghe $T$, Bogaert $P$, Laukens $B$, Zobel $K$, Deshayes $K$ et al. CIAP1 and TAK1 protect cells from TNF-induced necrosis by preventing RIP1/RIP3dependent reactive oxygen species production. Cell Death Differ 2011; 18: 656-665.

11. Vucur M, Reisinger F, Gautheron J, Janssen J, Roderburg C, Cardenas DV et al. RIP3 inhibits inflammatory hepatocarcinogenesis but promotes cholestasis by controlling caspase-8- and JNK-dependent compensatory cell proliferation. Cell Rep 2013; 4 776-790.

12. Omori E, Matsumoto K, Ninomiya-Tsuji J. Non-canonical $\beta$-catenin degradation mediates reactive oxygen species-induced epidermal cell death. Oncogene 2011; 30: 3336-3344.

13. Kajino-Sakamoto R, Inagaki M, Lippert E, Akira S, Robine S, Matsumoto K et al. Enterocytederived TAK1 signaling prevents epithelium apoptosis and the development of ileitis and colitis. J Immunol 2008; 181: 1143-1152.

14. Kim JY, Kajino-Sakamoto R, Omori E, Jobin C, Ninomiya-Tsuji J. Intestinal epithelial-derived TAK1 signaling is essential for cytoprotection against chemical-induced colitis. PLOS ONE 2009; 4: e4561.

15. Bevins CL, Salzman NH. Paneth cells, antimicrobial peptides and maintenance of intestina homeostasis. Nat Rev Microbiol 2011; 9: 356-368.

16. Sancho E, Batlle E, Clevers H. Live and let die in the intestinal epithelium. Curr Opin Cell Bio 2003; 15: 763-770.

17. Ireland $\mathrm{H}$, Houghton $\mathrm{C}$, Howard L, Winton DJ. Cellular inheritance of a Cre-activated reporter gene to determine Paneth cell longevity in the murine small intestine. Dev Dyn 2005; 233: 1332-1336.

18. Xavier RJ, Podolsky DK. Unravelling the pathogenesis of inflammatory bowel disease. Nature 2007; 448: 427-434.

19. Kaser A, Zeissig S, Blumberg RS. Inflammatory bowel disease. Annu Rev Immunol 2010; 28: 573-621.

20. Bry L, Falk P, Huttner K, Ouellette A, Midtvedt T, Gordon Jl. Paneth cell differentiation in the developing intestine of normal and transgenic mice. Proc Natl Acad Sci USA 1994; 91: 10335-10339.

21. McGuckin MA, Linden SK, Sutton P, Florin TH. Mucin dynamics and enteric pathogens Nat Rev Microbiol 2011; 9: 265-278.

22. Halliwell $B$, Whiteman $M$. Measuring reactive species and oxidative damage in vivo and in cell culture: how should you do it and what do the results mean? Br J Pharmacol 2004; 142: 231-255.

23. Liu Y, Collins C, Kiosses WB, Murray AM, Joshi M, Shepherd TR et al. A novel pathway spatiotemporally activates Rac1 and redox signaling in response to fluid shear stress. J Cell Biol 2013; 201: 863-873.

24. Lambeth JD, Neish AS. Nox enzymes and new thinking on reactive oxygen: a double-edged sword revisited. Annu Rev Pathol 2014; 9: 119-145.

25. Rakoff-Nahoum S, Paglino J, Eslami-Varzaneh F, Edberg S, Medzhitov R. Recognition of commensal microflora by toll-like receptors is required for intestinal homeostasis. Cell 2004 118: 229-241.

26. Lipinski S, Till A, Sina C, Arlt A, Grasberger H, Schreiber S et al. DUOX2-derived reactive oxygen species are effectors of NOD2-mediated antibacterial responses. J Cell Sci 2009; 122: $3522-3530$.

27. Laroux FS, Romero X, Wetzler L, Engel P, Terhorst C. Cutting edge: MyD88 controls phagocyte NADPH oxidase function and killing of gram-negative bacteria. J Immunol 2005: 175: $5596-5600$

28. West AP, Brodsky IE, Rahner C, Woo DK, Erdjument-Bromage $\mathrm{H}$, Tempst $\mathrm{P}$ et al. TLR signalling augments macrophage bactericidal activity through mitochondrial ROS. Nature 2011; 472: 476-480.
29. Kawai T, Akira S. The role of pattern-recognition receptors in innate immunity: update on Tolllike receptors. Nat Immunol 2010; 11: 373-384.

30. Hou B, Reizis B, DeFranco AL. Toll-like receptors activate innate and adaptive immunity by using dendritic cell-intrinsic and -extrinsic mechanisms. Immunity 2008; 29: 272-282.

31. Gunther C, Martini E, Wittkopf N, Amann K, Weigmann B, Neumann H et al. Caspase-8 regulates TNF-alpha-induced epithelial necroptosis and terminal ileitis. Nature 2011; 477: 335-339.

32. Welz PS, Wullaert A, Vlantis K, Kondylis V, Fernandez-Majada V, Ermolaeva M et al. FADD prevents RIP3-mediated epithelial cell necrosis and chronic intestinal inflammation. Nature 2011; 477: 330-334.

33. Vandenabeele P, Galluzzi L, Vanden Berghe T, Kroemer G. Molecular mechanisms of necroptosis: an ordered cellular explosion. Nat Rev Mol Cell Biol 2010; 11: 700-714.

34. Adolph TE, Tomczak MF, Niederreiter L, Ko HJ, Bock J, Martinez-Naves E et al. Paneth cells as a site of origin for intestinal inflammation. Nature 2013; 503: 272-276.

35. Ea CK, Deng L, Xia ZP, Pineda G, Chen ZJ. Activation of IKK by TNFalpha requires sitespecific ubiquitination of RIP1 and polyubiquitin binding by NEMO. Mol Cell 2006; 22: 245-257.

36. Takahashi N, Vereecke L, Bertrand MJ, Duprez L, Berger SB, Divert T et al. RIPK1 ensures intestinal homeostasis by protecting the epithelium against apoptosis. Nature 2014; 513: 95-99.

37. Dannappel M, Vlantis K, Kumari S, Polykratis A, Kim C, Wachsmuth L et al. RIPK1 maintains epithelial homeostasis by inhibiting apoptosis and necroptosis. Nature 2014; 513: 90-94.

38. Sato S, Sanjo H, Takeda K, Ninomiya-Tsuji J, Yamamoto M, Kawai T et al. Essential function for the kinase TAK1 in innate and adaptive immune responses. Nat Immunol 2005; 6: 1087-1095.

39. Pfeffer K, Matsuyama T, Kundig TM, Wakeham A, Kishihara K, Shahinian A et al. Mice deficient for the $55 \mathrm{kd}$ tumor necrosis factor receptor are resistant to endotoxic shock, yet succumb to L. monocytogenes infection. Cell 1993; 73: 457-467.

40. Madison BB, Dunbar L, Qiao XT, Braunstein K, Braunstein E, Gumucio DL. Cis elements of the villin gene control expression in restricted domains of the vertical (crypt) and horizontal (duodenum, cecum) axes of the intestine. J Biol Chem 2002; 277: 33275-33283.

41. el Marjou F, Janssen KP, Chang BH, Li M, Hindie V, Chan L et al. Tissue-specific and inducible Cre-mediated recombination in the gut epithelium. Genesis 2004; 39: 186-193.

42. Newton K, Sun X, Dixit VM. Kinase RIP3 is dispensable for normal NF- $\mathrm{KBs}$, signaling by the B-cell and T-cell receptors, tumor necrosis factor receptor 1, and Toll-like receptors 2 and 4 . Mol Cell Biol 2004; 24: 1464-1469.

43. Rath HC, Herfarth HH, Ikeda JS, Grenther WB, Hamm TE Jr., Balish E et al. Normal luminal bacteria, especially Bacteroides species, mediate chronic colitis, gastritis, and arthritis in HLA-B27/human beta2 microglobulin transgenic rats. J Clin Invest 1996; 98: 945-953.

44. Ninomiya-Tsuji J, Kishimoto K, Hiyama A, Inoue J, Cao Z, Matsumoto K. The kinase TAK1 can activate the NIK-IKB as well as the MAP kinase cascade in the IL-1 signalling pathway. Nature 1999; 398: 252-256

45. Maeda H, Fujimoto C, Haruki Y, Maeda T, Kokeguchi S, Petelin M et al. Quantitative realtime PCR using TaqMan and SYBR Green for Actinobacillus actinomycetemcomitans, Porphyromonas gingivalis, Prevotella intermedia, tetQ gene and total bacteria. FEMS Immunol Med Microbiol 2003; 39: 81-86.

46. Guo X, Xia X, Tang R, Zhou J, Zhao H, Wang K. Development of a real-time PCR method for Firmicutes and Bacteroidetes in faeces and its application to quantify intestinal population of obese and lean pigs. Lett Appl Microbiol 2008; 47: 367-373.

47. Subramanian M, Thorp E, Hansson GK, Tabas I. Treg-mediated suppression of atherosclerosis requires MYD88 signaling in DCs. J Clin Invest 2013; 123: 179-188.

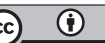

Cell Death and Disease is an open-access journal published by Nature Publishing Group. This work is licensed under a Creative Commons Attribution 4.0 International License. The images or other third party material in this article are included in the article's Creative Commons license, unless indicated otherwise in the credit line; if the material is not included under the Creative Commons license, users will need to obtain permission from the license holder to reproduce the material. To view a copy of this license, visit http://creativecommons.org/licenses/by/4.0/ 